\title{
A New Understanding of Stress Corrosion Cracking Mechanism of X80 Pipeline Steel at Passive Potential in High-pH Solutions
}

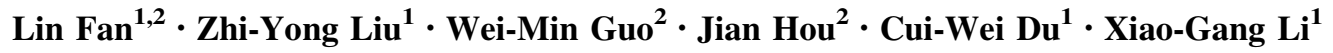

Received: 19 September 2014/Revised: 31 December 2014/Published online: 28 April 2015

(C) The Chinese Society for Metals and Springer-Verlag Berlin Heidelberg 2015

\begin{abstract}
Susceptibilities to stress corrosion cracking (SCC) of X80 pipeline steel in relatively concentrated carbonate/ bicarbonate solutions with different chloride ion concentrations or $\mathrm{pH}$ value at a passive potential of $-200 \mathrm{mV}$ vs SCE were investigated by slow strain rate tensile test. In order to explore the SCC mechanism and the evaluation criterion for the SCC susceptibility of the steel in passive state, electrochemical measurements were taken. Potentiodynamic polarization curves were obtained at different potential sweep rates, and electrochemical impedance spectroscopy measurements were taken after fast polarization to the passive potential. The effects of chloride ion and $\mathrm{pH}$ on SCC behaviors of X80 steel at the passive potential were also discussed. The results showed that the SCC mechanism of X80 pipeline steel was greatly influenced by the passive film formed in these solutions. The SCC behaviors followed the film suppressed anodic dissolution mechanism in these circumstances, because the filming process accounted for a considerable proportion of the overall electrode process. The criteria for evaluating the SCC susceptibility of the steel at passive potential were proposed and validated. Decreasing in the concentration of chloride ion or increasing in $\mathrm{pH}$ value resulted in the reduction in SCC susceptibility. The existence of chloride ion greatly lowered the passivation tendency and the film stability, while its concentration determined the dissolution rate of the steel matrix. Higher $\mathrm{pH}$ value was responsible for the stable and tenacious passive films and the high repassivation capability. It was also inclined to lower the anodic dissolution rate at crack tips by retarding the cathodic oxygen reduction.
\end{abstract}

KEY WORDS: Pipeline steel; Stress corrosion cracking (SCC); Passivation; Chloride ion; pH value

\section{Introduction}

Since the first case of stress corrosion cracking (SCC) was reported in 1965, the SCC behavior of pipeline steels has received much attention [1]. It is widely known that the

Available online at http://link.springer.com/journal/40195

Zhi-Yong Liu

liuzhiyong7804@126.com

1 Corrosion and Protection Center, University of Science and Technology Beijing, Beijing 100083, China

2 State Key Laboratory for Marine Corrosion and Protection, Luoyang Ship Material Research Institute, Qingdao 266101, China
SCC of pipeline steels can be categorized into two types, i.e., high-pH SCC and near-neutral-pH SCC [2, 3]. As ordinarily reported, high-pH SCC is characterized by numerous fine and shallow cracks. They are usually found in aerated, relatively concentrated carbonate/bicarbonate solutions with $\mathrm{pH}$ value of 8-11 [4-6]. When sufficient cathodic current at pipeline surface is available, the $\mathrm{pH}$ value of the solution outside the pipeline can even reach to 11-12 [7]. It has been well accepted that high-pH SCC is primarily attributed to the dissolution-based mechanism, i.e., cracking being facilitated by anodic dissolution and repeated rupture of passive films formed over crack tips under the stress [8]. Therefore, the properties of passive film formed on pipeline steel are critical to corrosion and SCC behaviors of the steel [9-11]. Theoretically, passivation is extremely useful in mitigating corrosion damage; 
however, even a high-quality alloy will be corroded if its ability to form a protective passive film is hindered. If breakdown occurs in passive film, the material will suffer from pitting and SCC. So far, extensive studies [12-16] have been performed to reveal that the existence of various solvated species such as chloride, bicarbonate, and carbonate ions is in close relationship with the film formation process and the properties of the film. This therefore affects the initiation and propagation of the stress corrosion cracks. However, there has been limited work in investigating the SCC behavior and mechanism of X80 pipeline steel in passive state when various solvated ions coexist in high-pH solutions.

For the susceptibility to SCC of pipeline steel, Parkins $[17,18]$ pointed out that it could be evaluated by the potentiodynamic polarization measurements at different potential sweep rates. Scanning at a fast sweep rate would extremely eliminate the influence of the formation of passive films, guaranteeing a fresh metal surface exposed to the electrolyte. Since intensive anodic dissolution took place at this sweep rate, it could reflect the electrochemical characteristic at the crack tips. At the slow sweep rate for polarization, the metal surface could be sufficiently passivated, which manifested the electrochemical characteristic of non-crack tip areas. Based on this understanding, our group developed the criteria for evaluating the susceptibility to SCC of pipeline steel corresponding different SCC mechanism [19]. When the SCC behavior is mainly controlled by anodic dissolution, the relationship between the theoretical susceptibility to SCC $\left(I_{\mathrm{SCC}}\right)$ and the polarization current densities is as follows:

$I_{\mathrm{SCC}}=k_{\mathrm{a}} \cdot i_{\mathrm{f}} \cdot\left(\frac{i_{\mathrm{f}}-i_{\mathrm{s}}}{i_{\mathrm{S}}}\right)+I_{\mathrm{a}}$,

where $i_{\mathrm{f}}$ and $i_{\mathrm{s}}$ obtained at the given potential are the polarization current densities at the fast and slow sweep rates, respectively. $i_{\mathrm{f}}$ represents the propagation rate of crack tips, and $\left(i_{\mathrm{f}}-i_{\mathrm{s}}\right) i_{\mathrm{s}}$ represents the discrepancy between corrosion rates of crack tip and non-crack tip areas. The higher the values of $i_{\mathrm{f}}$ and $\left(i_{\mathrm{f}}-i_{\mathrm{s}}\right) i_{\mathrm{s}}$ are, the faster the cracks grow. $k_{\mathrm{a}}$ is the coefficient associated with the current density and the type of material and electrolyte. $I_{\mathrm{a}}$ is the nominal susceptibility when $i_{\mathrm{f}}=i_{\mathrm{s}}$.

When the SCC is primarily controlled by hydrogen embrittlement, $I_{\mathrm{SCC}}$ can be expressed as:

$I_{\mathrm{SCC}}=k_{\mathrm{h}} \cdot\left|i_{\mathrm{S}}\right|+I_{\mathrm{h}}$,

where the influence of cathodic hydrogen evolution is measured in terms of $\left|i_{\mathrm{s}}\right| k_{\mathrm{h}}$ refers to the intensity factor of hydrogen embrittlement. $I_{\mathrm{h}}$ is the nominal susceptibility when $i_{\mathrm{s}}$ is equal to the corrosion current density $\left(i_{\text {corr }}\right)$.
While it is a combination of anodic dissolution and hydrogen embrittlement, $I_{\mathrm{SCC}}$ should be calculated by:

$I_{\mathrm{SCC}}=k_{\mathrm{a}} \cdot i_{\mathrm{f}} \cdot\left(\frac{i_{\mathrm{f}}-i_{\mathrm{s}}}{i_{\mathrm{s}}}\right)+k_{\mathrm{h}} \cdot\left|i_{\mathrm{s}}\right|+I_{\mathrm{c}}$,

where $I_{\mathrm{c}}$ is the additional susceptibility on considering the combined effect of anodic dissolution and hydrogen embrittlement.

It has been proved in our later research that the above criteria were applicable for the steels in anodic dissolution or cathodic protection state [20]. But there is still lack of the information on the SCC mechanism and the relevant criteria for evaluating SCC susceptibility of X80 steel at passive potential. In this work, SCC susceptibilities of X80 pipeline steel in high-pH solutions with different concentrations of chloride ion or $\mathrm{pH}$ value at a passive potential were investigated by slow strain rate tensile (SSRT) test. By means of potentiodynamic polarization curves obtained at different potential sweep rates and electrochemical impedance spectroscopy (EIS) measurements, the SCC mechanism of the steel and the corresponding evaluation criterion for the susceptibility to SCC were formulated. The effect of chloride ion and $\mathrm{pH}$ on SCC behavior of X80 steel at the passive potential was also discussed.

\section{Experimental}

\subsection{Specimens and Solutions}

The specimens used in this work were made of X80 pipeline steel supplied by Bao Steel Co. Ltd., with the chemical composition (wt\%) of $0.036 \mathrm{C}, 0.197 \mathrm{Si}, 1.771$ Mn, 0.012 P, $0.002 \mathrm{~S}, 0.223 \mathrm{Cr}, 0.278 \mathrm{Ni}, 0.220 \mathrm{Cu}, 0.021$ $\mathrm{Al}, 0.019 \mathrm{Ti}, 0.184 \mathrm{Mo}, 0.001 \mathrm{~V}, 0.110 \mathrm{Nb}, 0.005 \mathrm{~N}$, and $\mathrm{Fe}$ balance. Its yielding strength was $640 \mathrm{MPa}$, and the ultimate tensile strength was $750 \mathrm{MPa}$. The specimens used in conventional electrochemical measurements were embedded in epoxy resin with the working area of $1.0 \mathrm{~cm}^{2}$. For SSRT test, smooth flat tensile specimens were used with the gauge size of $36 \mathrm{~mm} \times 6 \mathrm{~mm} \times 2 \mathrm{~mm}$. The long axis of the specimens was parallel to the circumferential direction of the steel pipe. Prior to the test, all the specimens were grounded from 60- up to 1000-grit silicon carbide paper, then rinsed with deionized water, and degreased in acetone.

In order to investigate the influence of chloride ion and $\mathrm{pH}$ on SCC behaviors of X80 steel separately, two types of testing solutions were used: (1) $0.05 \mathrm{~mol} / \mathrm{L} \quad \mathrm{Na}_{2}$ $\mathrm{CO}_{3}+0.10 \mathrm{~mol} / \mathrm{L} \mathrm{NaHCO}_{3}$ solutions without and with different concentrations of $\mathrm{NaCl}(0.01-0.10 \mathrm{~mol} / \mathrm{L})$, whose $\mathrm{pH}$ value was kept at approximately 8.31, and (2) $0.15 \mathrm{~mol} /$ L $\mathrm{Na}_{2} \mathrm{CO}_{3} / \mathrm{NaHCO}_{3}+0.10 \mathrm{~mol} / \mathrm{L} \mathrm{NaCl}$ solutions, of 
which the $\mathrm{pH}$ values were adjusted by changing the relative concentrations of $\mathrm{Na}_{2} \mathrm{CO}_{3}$ and $\mathrm{NaHCO}_{3}$. All the solutions were prepared by mixing analytical grade reagents with deionized water, and all the tests were performed at ambient temperature.

\subsection{Experimental Methods}

The strain rate was controlled at $1 \times 10^{-6} \mathrm{~s}^{-1}$. During the test, a passive potential of $-200 \mathrm{mV}$ versus SCE was adopted, which was chosen according to the potentiodynamic polarization curves. Reduction-in-area loss $\left(I_{\psi}\right)$ and fracture strength loss $\left(I_{\sigma}\right)$ were introduced to quantify the SCC susceptibility, which are defined as [21]:

$I_{\psi}=\frac{\psi_{0}-\psi_{\mathrm{E}}}{\psi_{0}} \times 100 \%$,

$I_{\sigma}=\frac{\sigma_{0}-\sigma_{\mathrm{E}}}{\sigma_{0}} \times 100 \%$,

where $\psi_{\mathrm{E}}, \psi_{0}, \sigma_{\mathrm{E}}$, and $\sigma_{0}$ were corresponding the reduction-in-area and the fracture strength in solution and in air, respectively. The fracture morphologies of the cross-side and the surfaces of tensile specimens after the SSRT test were observed by scanning electron microscopy (SEM).

Electrochemical experiments were performed with PARSTAT 2273, using a conventional three-electrode cell system, where X80 steel was used as the working electrode, a saturated calomel electrode (SCE) as the reference electrode, and a platinum sheet as the auxiliary electrode. All the potentials quoted in this work were referred to SCE. Prior to the test, all the electrodes were immersed in solutions until the open-circuit potential (OCP) was stable. Potentiodynamic polarization curves were acquired by scanning from -1500 to $1500 \mathrm{mV}$ versus SCE at a slow sweep rate of $1 \mathrm{mV} / \mathrm{s}$ and a fast sweep rate of $100 \mathrm{mV} / \mathrm{s}$. EIS measurements were taken at $-200 \mathrm{mV}$ versus SCE after the steel was polarized to this passive potential at $100 \mathrm{mV} / \mathrm{s}$. The frequency was controlled from $100 \mathrm{kHz}$ to $10 \mathrm{mHz}$.

\section{Results}

\subsection{SCC Susceptibilities of X80 Steel in the Solutions with Different Concentrations of Chloride Ion}

The stress-strain curves of $\mathrm{X} 80$ pipeline steel in $0.05 \mathrm{~mol} / \mathrm{L} \quad \mathrm{Na}_{2} \mathrm{CO}_{3}+0.10 \mathrm{~mol} / \mathrm{L} \quad \mathrm{NaHCO}_{3}$ solutions with different concentrations of chloride ion at $-200 \mathrm{mV}$ versus SCE are shown in Fig. 1. Compared with the curve obtained in air, X80 steel in testing solutions displayed susceptibility to SCC. With the increase in chloride ion

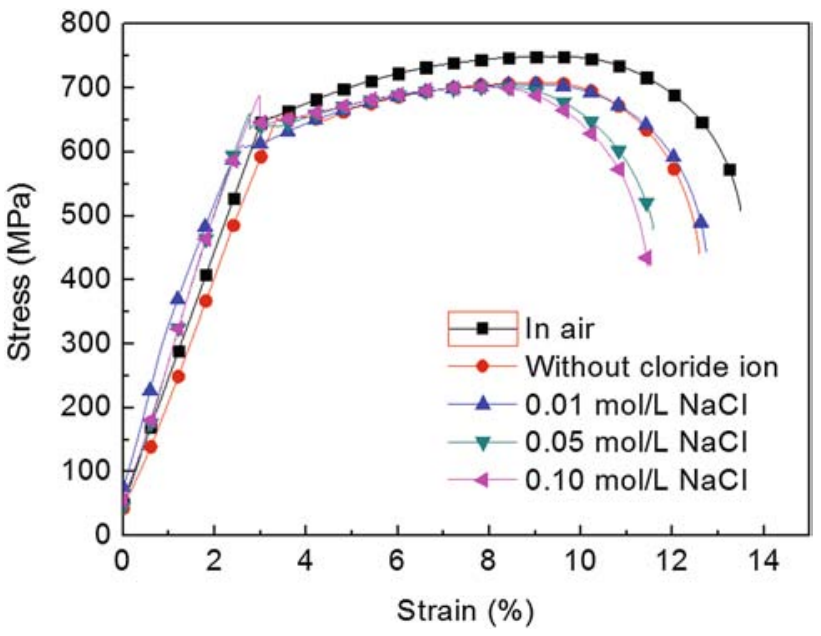

Fig. 1 Stress-strain curves of $\mathrm{X} 80$ pipeline steel in air and in $0.05 \mathrm{~mol} / \mathrm{L} \mathrm{Na}_{2} \mathrm{CO}_{3}+0.10 \mathrm{~mol} / \mathrm{L} \mathrm{NaHCO}_{3}$ solutions with different concentrations of chloride ion at $-200 \mathrm{mV}$ versus SCE

concentration, the susceptibility increased with the reduction in the fracture area and the strength, which was manifested in the elevated values of $I_{\psi}$ and $I_{\sigma}$ in Fig. 2 . These results were further confirmed by the observation of the fracture morphologies shown in Fig. 3. In solution without chloride ion, the steel showed a low susceptibility to SCC. A dimple-like feature can be found on the fracture surface (Fig. 3a), and there were no visible pitting but shallow and short secondary cracks initiated on the lateral surface (Fig. 3b). When chloride ion existed and increased in amount, the dimple feature was reduced (Fig. 3c), and numeral micro-pits evolved along the slip step and coalesced to form cracks. Micro-cracks were also spotted on the facture surface (Fig. 3d).

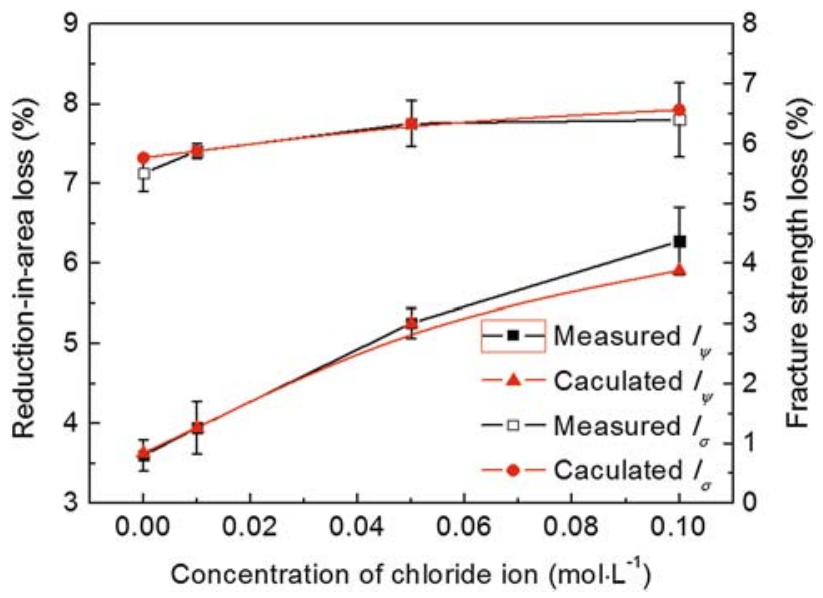

Fig. 2 Measured and calculated data of reduction-in-area loss and fracture strength loss in the solutions with different chloride ion concentrations 

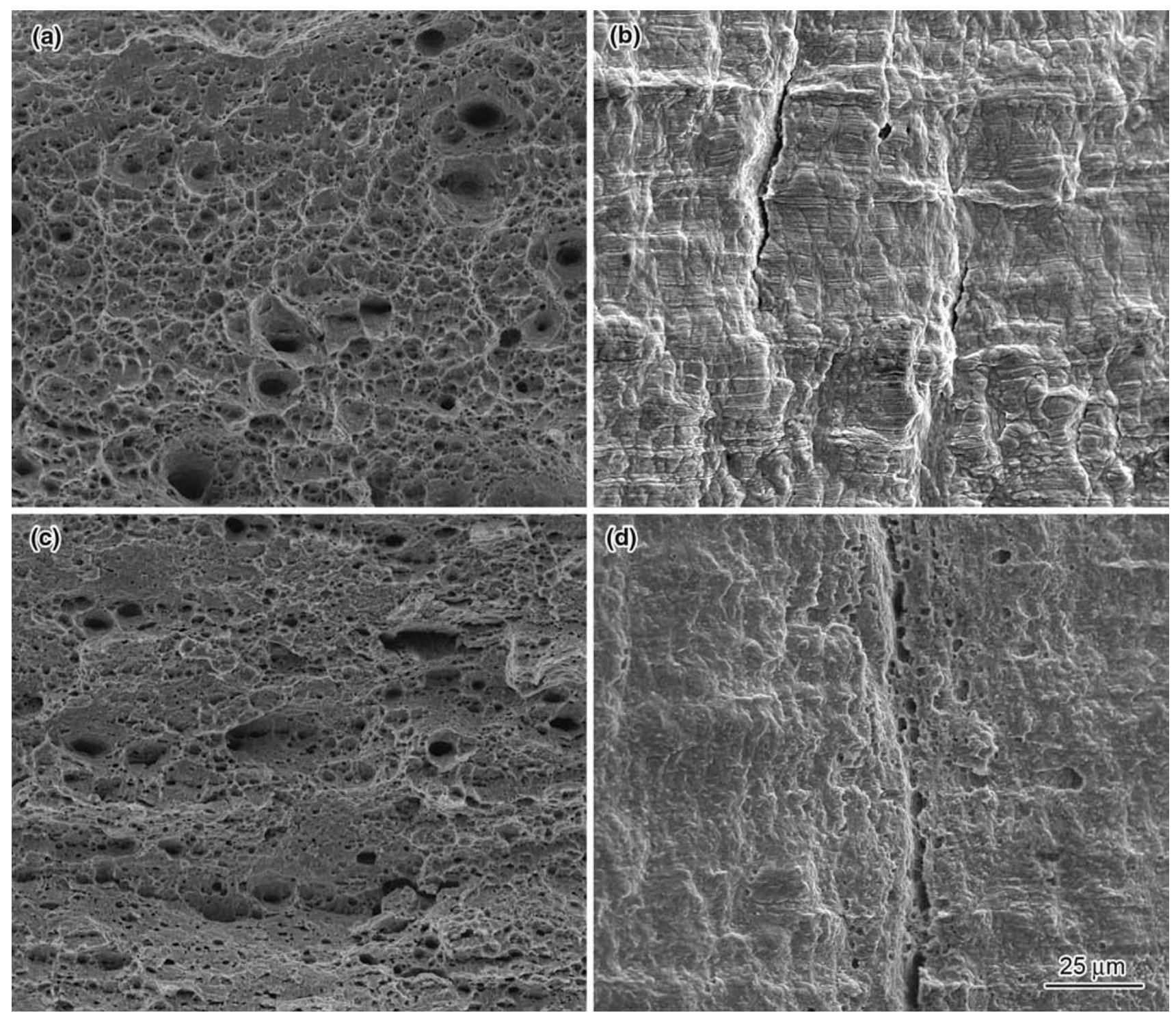

Fig. 3 Morphologies of fracture surfaces a, $\mathbf{c}$ and lateral surfaces $\mathbf{b}, \mathbf{d}$ in $0.05 \mathrm{~mol} / \mathrm{L} \mathrm{Na}_{2} \mathrm{CO}_{3}+0.10 \mathrm{~mol} / \mathrm{L} \mathrm{NaHCO}$ solutions without chloride ion $\mathbf{a}, \mathbf{b}$, with $0.10 \mathrm{~mol} / \mathrm{L}$ chloride ion $\mathbf{c}, \mathbf{d}$

\subsection{SCC Susceptibilities of X80 Steel in the Solutions with Different pH Values}

Figures 4 and 5 exhibit the SSRT results of X80 pipeline steel in $0.15 \mathrm{~mol} / \mathrm{L} \mathrm{Na}_{2} \mathrm{CO}_{3} / \mathrm{NaHCO}_{3}+0.10 \mathrm{~mol} / \mathrm{L} \mathrm{NaCl}$ solutions with different $\mathrm{pH}$. X80 steel showed significant susceptibility to SCC with respect to low $\mathrm{pH}$ value $(\mathrm{pH}=8.31)$, which was reflected by the much higher $I_{\psi}$ and $I_{\sigma}$. Instead of dimple feature, the fractograph displayed quasi-cleavage morphology (Fig. 6a). On the lateral surface, colonies of secondary cracks were found to initiate and propagate along the slip steps (Fig. 6b). Brittle cracking feature can also be found at the edge of the fracture surface (Fig. 6c). Moreover, the coarse and pitted specimen surfaces indicated that the specimen also suffered from severe anodic dissolution during cracking. As $\mathrm{pH}$ value increased, SCC resistance of the steel was enhanced intensively. Especially when $\mathrm{pH}$ rose up to 11.64 , both the reduction-in-area and the fracture strength hardly showed any decrease relative to those in air. The fracture surface showed a typical dimple feature (Fig. 6d), and there were no pits and cracks found on the lateral surface. It suggested that X80 steel almost had no SCC susceptibility in the solution with such a high $\mathrm{pH}$ value.

\subsection{Polarization Characteristics}

Figure 7 shows the polarization curves of X80 steel at different potential sweep rates in the solutions with different chloride ion concentrations or $\mathrm{pH}$. Passive region 


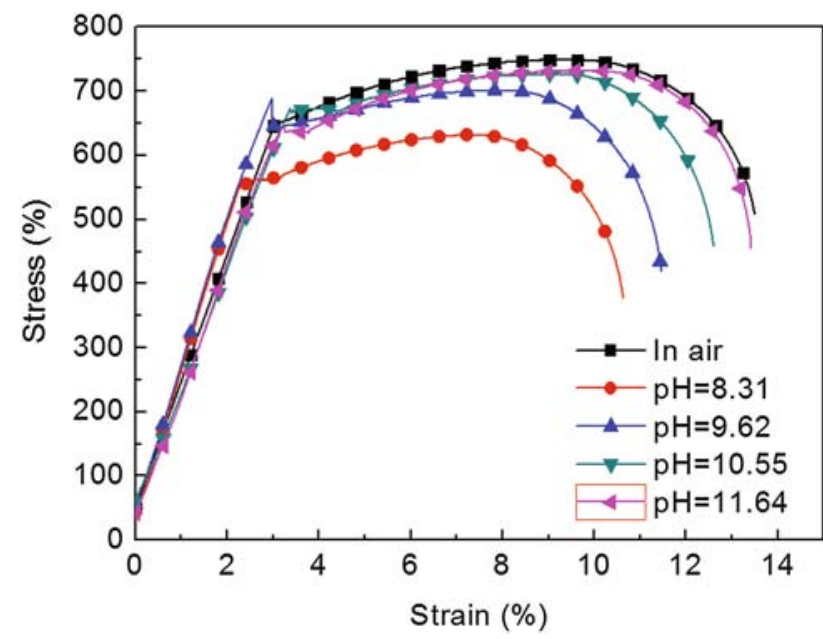

Fig. 4 Stress-strain curves of $\mathrm{X} 80$ pipeline steel in air and in $0.15 \mathrm{~mol} / \mathrm{L} \mathrm{Na} \mathrm{CO}_{3} / \mathrm{NaHCO}_{3}+0.10 \mathrm{~mol} / \mathrm{L} \mathrm{NaCl}$ solutions with different $\mathrm{pH}$ at $-200 \mathrm{mV}$ versus SCE

existed in the solutions with the $\mathrm{pH}$ value higher than 9.62, just in which the applied potential of $-200 \mathrm{mV}$ versus SCE was chosen. If the SCC behavior was assumed to be controlled by the anodic dissolution mechanism, $i_{\mathrm{f}} \cdot\left(i_{\mathrm{f}}-i_{\mathrm{s}}\right) / i_{\mathrm{s}}$ can be used to estimate the SCC susceptibility of X80 steel [17]. However, $i_{\mathrm{f}} \cdot\left(i_{\mathrm{f}}-i_{\mathrm{s}}\right) / i_{\mathrm{s}}$ did not conform to the variation rules of $I_{\psi}$ and $I_{\sigma}$ when the chloride ion was absent or the $\mathrm{pH}$ value changed from 8.31 to 11.64 as shown in Fig. 8. Therefore, the previous assumption was not tenable. The SCC behavior of X80 steel may not be explained simply by anodic dissolution mechanism in these circumstances.

\section{Discussion}

\subsection{Electrochemical Criterion for Evaluating the Susceptibility to SCC at Passive Potential}

As shown in Fig. 7, all the curves obtained at a slow sweep rate of $1 \mathrm{mV} / \mathrm{s}$ included an anodic current peak at about $-600 \mathrm{mV}$ versus SCE which was considered to be the initiating passive potential. The corresponding anodic oxidation reaction was the dissolution of metallic iron. In carbonate/bicarbonate solutions, the reaction products should be ferrous carbonate and/or hydroxide as follows [22]:

$\mathrm{Fe}+2 \mathrm{H}_{2} \mathrm{O} \rightarrow \mathrm{Fe}(\mathrm{OH})_{2}+2 \mathrm{H}^{+}+2 \mathrm{e}^{-}$,

$\mathrm{Fe}+\mathrm{HCO}_{3}^{-} \rightarrow \mathrm{FeCO}_{3}+\mathrm{H}^{+}+2 \mathrm{e}^{-}$,

$\mathrm{Fe}^{2+}+\mathrm{CO}_{3}^{2-} \rightarrow \mathrm{FeCO}_{3}$.

The reactions (6)-(8) are favored by high $\mathrm{pH}, \mathrm{HCO}_{3}{ }^{-}$ and $\mathrm{CO}_{3}{ }^{2-}$ concentration. A second peak appeared at

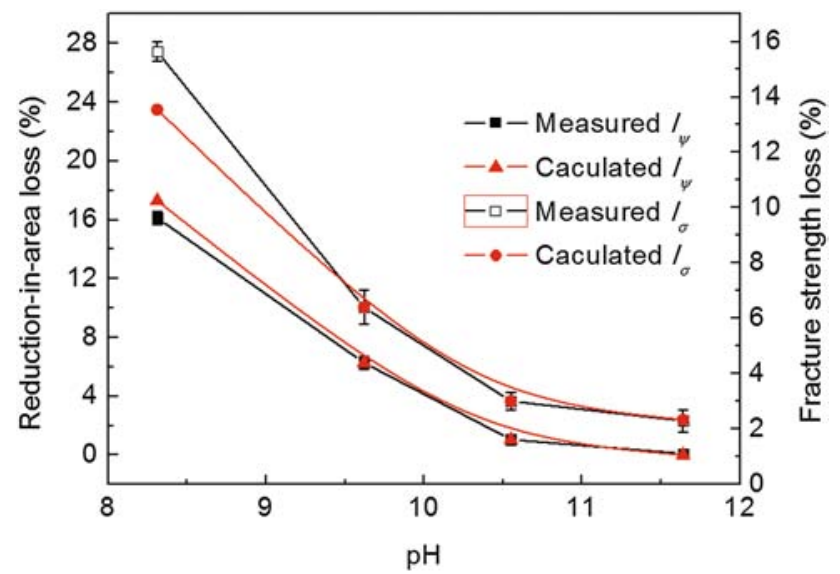

Fig. 5 Measured and calculated data of reduction-in-area loss and fracture strength loss in the solutions with different $\mathrm{pH}$

around $-300 \mathrm{mV}$ versus SCE. Above this potential, the ferrous ions were further oxidized to form more stable ferric oxide film. Referring to the literature [23], the ferric oxide film was the primary cause of passivation in these solutions, and the reactions can be expressed as follows:

$4 \mathrm{Fe}(\mathrm{OH})_{2}+\mathrm{O}_{2} \rightarrow 2 \mathrm{Fe}_{2} \mathrm{O}_{3}+4 \mathrm{H}_{2} \mathrm{O}$,

$4 \mathrm{FeCO}_{3}+\mathrm{O}_{2}+8 \mathrm{OH}^{-} \rightarrow 2 \mathrm{Fe}_{2} \mathrm{O}_{3}+4 \mathrm{CO}_{3}^{2-}+4 \mathrm{H}_{2} \mathrm{O}$.

The reaction (10) is also favored by high $\mathrm{pH}$. These results are consistent with Liu and Mao's report [24]. In light of these, the following SCC mechanism should still be based on, i.e., cracking being attributed to repeated anodic dissolution and rupture of passive films formed over the crack tip [25]. Therefore, the SCC susceptibilities were believed to depend on the tenacity and stability of passive films formed on the specimen surface [4].

In addition, an obvious passive region can also be seen when the steel was polarized at a fast sweep rate of $100 \mathrm{mV} / \mathrm{s}$. This was different from the result in an acidic soil environment observed by Liu et al. [21]. It seemed inappropriate to evaluate the electrochemical characteristic of non-crack tip area by using $i_{\mathrm{f}}$ directly, because the influence of filming process was not negligible. And it can be deduced that the current density representing the anodic dissolution of bare metal only accounts for a certain proportion of $i_{\mathrm{f}}$. However, in view of the strong non-Faradaic process evoked by an extraordinarily high sweep rate, the application of excessive polarization rate to eliminate the redox reaction occurred in passive films is inadvisable. So the concerned proportion of current density must be extracted from $i_{\mathrm{f}}$. In this work, a distinctive EIS measurement after fast polarization of the steel to the given potential was designed. Because the EIS measurement can avoid any change in surface conditions of the specimens after fast 

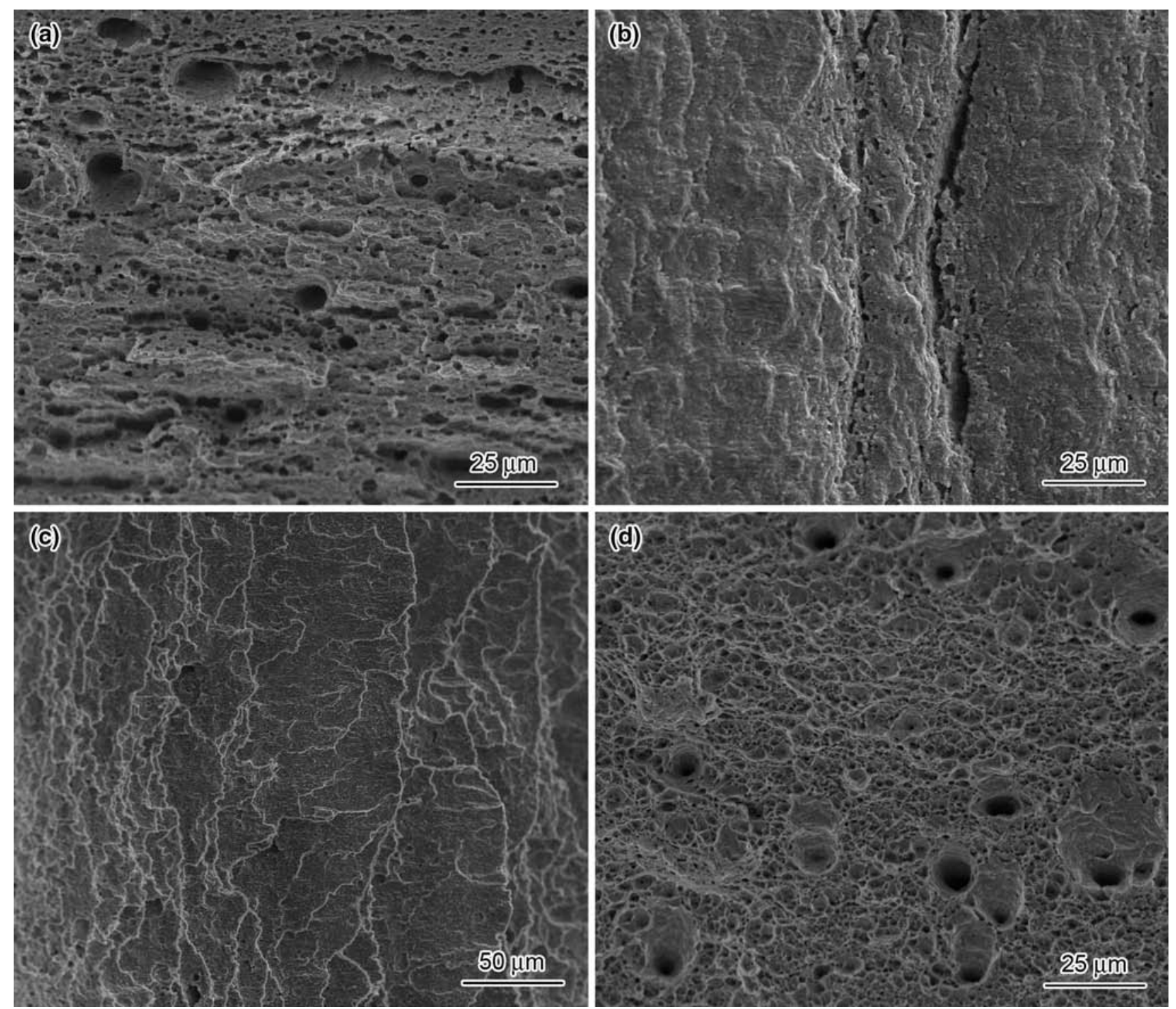

Fig. 6 Morphologies of fracture surfaces a, $\mathbf{d}$ and lateral surfaces $\mathbf{b}$, $\mathbf{c}$ in $0.15 \mathrm{~mol} / \mathrm{L} \mathrm{Na}_{2} \mathrm{CO}_{3} / \mathrm{NaHCO}_{3}+0.10 \mathrm{~mol} / \mathrm{L} \mathrm{NaCl}$ solutions with $\mathrm{pH}=8.31 \mathbf{a}-\mathbf{c}, \mathrm{pH}=11.64 \mathbf{d}$

polarization, it was reasonable to use this method to illustrate the polarization characteristics of the steel at $-200 \mathrm{mV}$ versus SCE.

As shown in Fig. 9, the plots were comprised of two capacitance arcs except for $\mathrm{pH}=8.31$. The one at high frequency corresponded to the electric double layer; the other at low-mediate frequency was related to the passive film, so that the Faradaic impedance can be described as

$Z_{\mathrm{F}}^{0}=R_{\mathrm{ct}}+\frac{R_{\mathrm{po}}}{1+j \omega R_{\mathrm{po}} C_{\mathrm{pf}}}$,

where $R_{\mathrm{ct}}$ is the charge transfer resistance, $R_{\mathrm{po}}$ is the pore resistance of passive film, $C_{\mathrm{pf}}$ is the passive film capacitance, and $\omega=2 \pi f$ represents the angular frequency of sinusoidal electrical signal. In the solution with a pH value of 8.31, there was only one capacitance arc appeared in the Nyquist plot as shown in the inset graph of Fig. 9b. The Faradaic impedance in this solution can be expressed by

$Z_{\mathrm{F}}^{0}=R_{\mathrm{ct}}$.

For the overall electrode process, the non-Faradaic process should also be included, and the overall impedance is as follows:

$Z=R_{\mathrm{s}}+\frac{1}{j \omega C_{\mathrm{dl}}+\frac{1}{Z_{F}^{0}}}$,

where $R_{\mathrm{s}}$ is the solution resistance and $C_{\mathrm{dl}}$ is the electrical double layer capacitance. The equivalent circuits according 

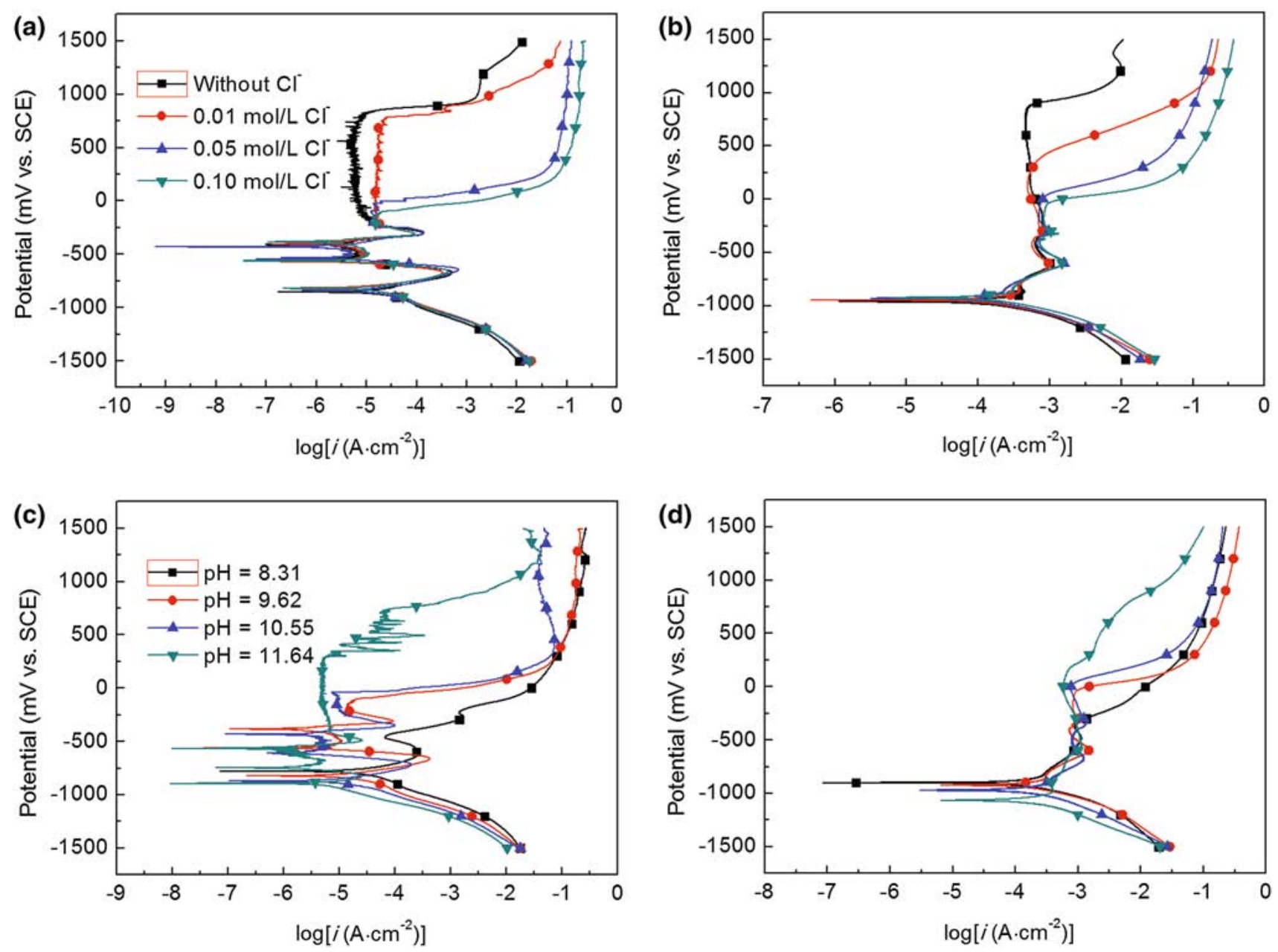

Fig. 7 Polarization curves of X80 steel at sweep rates of $1 \mathrm{mV} / \mathrm{s}$ a, $\mathbf{c}$ and $100 \mathrm{mV} / \mathrm{s} \mathrm{b}$, d in the solutions with different chloride ion concentrations $\mathbf{a}, \mathbf{b}$ and $\mathrm{pH} \mathbf{c}, \mathbf{d}$

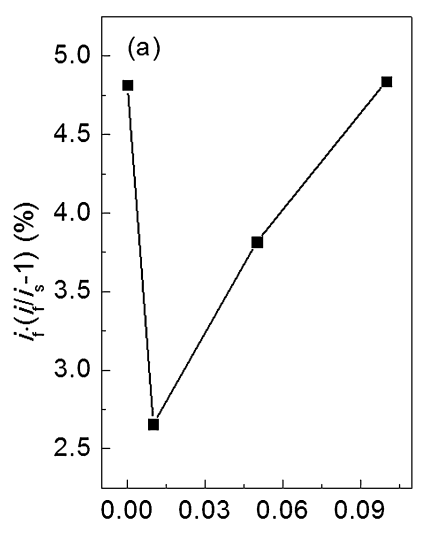

Chloride ion concentration (mol. $\left.\mathrm{L}^{-1}\right)$

Fig. 8 Relationship between $i_{\mathrm{f}} \cdot \frac{i_{\mathrm{f}}-i_{\mathrm{s}}}{i_{\mathrm{s}}}$ and chloride ion concentration a and $\mathrm{pH} \mathbf{b}$

to Eq. (13) are shown in Fig. 10, where $C_{\mathrm{dl}}$ and $C_{\mathrm{pf}}$ were replaced by the constant phase elements, i.e., $Q_{\mathrm{dl}}$ and $Q_{\mathrm{pf}}$, in view of the dispersion effect. Since the polarization resistance, i.e., $R_{\mathrm{p}}$ is defined as $\left(Z_{\mathrm{F}}\right)_{\omega=0}$, it can be inferred from Eqs. (11) and (12) that the resistance of the overall electrode process at the applied passive potential can be determined by $R_{\mathrm{p}}$. And it is in the forms of $R_{\mathrm{ct}}+R_{\mathrm{po}}$ and $R_{\mathrm{ct}}$, respectively. The fitting data listed in Table 1 showed that both $R_{\mathrm{ct}}$ and $R_{\mathrm{po}}$ increased with the decrease in salinity and increase in alkaline, suggesting a reduced corrosion rate. These were in accordance with the observations that X80 steel primarily showed mechanical failure with a ductile-type fractograph in the solutions without chloride ion or with higher $\mathrm{pH}$ value.

It was then assumed that the current density measured at $100 \mathrm{mV} / \mathrm{s}$ included the part consumed on the anodic dissolution of bare metal according to reactions (6)-(8) and on the formation of ferric oxide film according to reactions (9) and (10). Based on the definitions of $R_{\mathrm{ct}}$ and $R_{\mathrm{po}}, R_{\mathrm{ct}}$ may represent the former part and $R_{\mathrm{po}}$ the latter part in this work. Meanwhile, when a constant potential or direct current was applied and $R_{\mathrm{S}}$ was low enough to be ignored, the impedance $Z$ of the equivalent circuit shown in Fig. 10a 

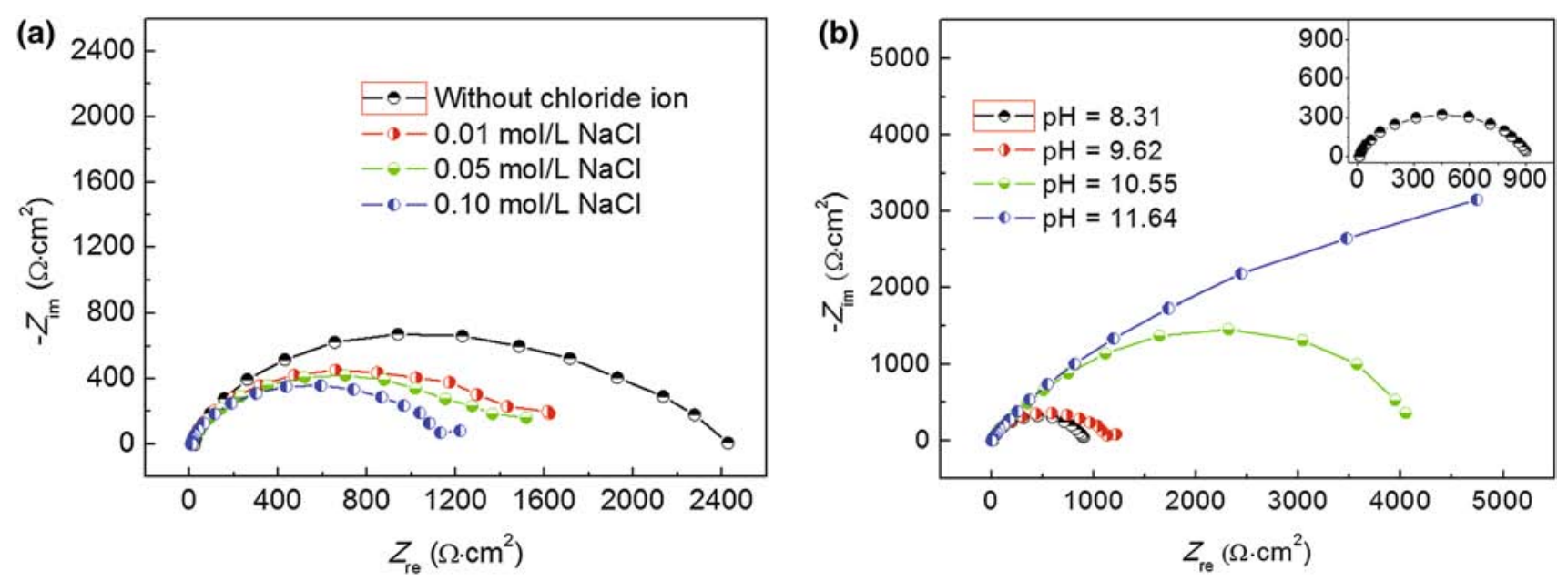

Fig. 9 EIS results of X80 steel in the solutions with different concentrations of chloride ion $\mathbf{a}$ and different $\mathrm{pH} \mathbf{b}$; inset is the magnification for $\mathrm{pH}=8.31$

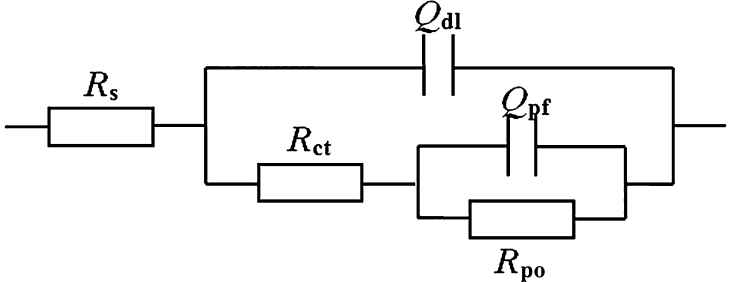

(a)

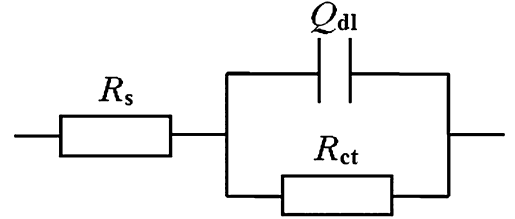

(b)

Fig. 10 Equivalent circuits corresponding to the EIS results in the solutions with different chloride ion concentrations or with pH higher than $9.62 \mathbf{a}$ and in the solutions with a $\mathrm{pH}$ value of $8.31 \mathbf{b}$

Table 1 Fitting data of $R_{\mathrm{ct}}, R_{\mathrm{po}}$, and $R_{\mathrm{p}}$

\begin{tabular}{|c|c|c|c|c|c|c|c|c|}
\hline \multirow[t]{2}{*}{ Fitting data $\left(\Omega \mathrm{cm}^{2}\right)$} & \multicolumn{4}{|c|}{ Chloride ion concentration $\left(\mathrm{mol} \mathrm{L}^{-1}\right)$} & \multicolumn{4}{|l|}{$\mathrm{pH}$} \\
\hline & 0 & 0.01 & 0.05 & 0.10 & 8.31 & 9.62 & 10.64 & 11.55 \\
\hline$R_{\mathrm{ct}}$ & 375 & 363.8 & 289.5 & 221.9 & 922.4 & 221.9 & 310.7 & 555.9 \\
\hline$R_{\mathrm{po}}$ & 1997.9 & 1286 & 1124 & 940 & - & 940 & 4113 & 11,770 \\
\hline$R_{\mathrm{p}}$ & 2372.9 & 1649.8 & 1413.5 & 1161.9 & 922.4 & 1161.9 & 4423.7 & $12,325.9$ \\
\hline
\end{tabular}

is equal to $R_{\mathrm{p}}$. Thus, the proportion of anodic dissolution of bare metal in $i_{\mathrm{f}}$ can be expressed by

$i^{*}=\frac{R_{\mathrm{ct}}}{R_{\mathrm{p}}} \cdot i_{\mathrm{f}}$,

Furthermore, the ratio of $R_{\mathrm{ct}} / R_{\mathrm{p}}$ decreased with the decrease in salinity and increase in alkaline. In this case, intensive filming process dominated the overall electrode reaction rate, leading to a dense and stable passive film with superior protection. This passive film can effectively suppress the diffusion of aggressive ions to the steel surface and mitigate the dissolution of the steel matrix or crack tips. Consequently, the dissolution of crack tips significantly lagged behind mechanical cracking, which resulted in the low SCC susceptibilities of X80 steel.

By replacing $i_{\mathrm{f}}$ in Eq. (1) with $i^{*}, I_{\mathrm{SCC}}$ relevant to these circumstances can be formulated as

$$
\begin{aligned}
I_{\mathrm{SCC}} & =k_{\mathrm{a}} \cdot i^{*} \cdot\left(\frac{i^{*}-i_{\mathrm{s}}}{i_{\mathrm{s}}}\right)+I_{\mathrm{a}} \\
& =k_{\mathrm{a}} \cdot\left(\frac{R_{\mathrm{ct}}}{R_{\mathrm{p}}} \cdot i_{\mathrm{f}}\right) \cdot\left(\frac{R_{\mathrm{ct}} \cdot i_{\mathrm{f}}-R_{\mathrm{p}} \cdot i_{\mathrm{s}}}{R_{\mathrm{p}} \cdot i_{\mathrm{s}}}\right)+I_{\mathrm{a}} .
\end{aligned}
$$

Equation (15) indicated that this criterion was still in the basic form claimed in Ref. [19], but the factor associated with the suppression effect of passive films was incorporated as a modifier. By applying the results of $I_{\psi}$ and $I_{\sigma}$, the values of $k_{\mathrm{a}}$ and $I_{\mathrm{a}}$ were estimated. Finally, $I_{\mathrm{SCC}}$ 
used for evaluating the SCC susceptibility of X80 steel at passive potential in solutions with different chloride ion concentrations or $\mathrm{pH}$ is given as follows:

$I_{\mathrm{SCC}\left(\mathrm{Cl}^{-}\right)}=\left\{\begin{array}{ll}4232.956 \cdot i^{*} \cdot\left(\frac{i^{*}}{i_{\mathrm{s}}}-1\right)-1.016 \%, & \text { for } I_{\psi} \\ 1486.381 \cdot i^{*} \cdot\left(\frac{i^{*}}{i_{\mathrm{S}}}-1\right)+4.136 \%, & \text { for } I_{\sigma}\end{array}\right.$,

$I_{\mathrm{SCC}(\mathrm{pH})}=\left\{\begin{array}{ll}4315.381 \cdot i^{*} \cdot\left(\frac{i^{*}}{i_{\mathrm{s}}}-1\right)-0.782 \%, & \text { for } I_{\psi} \\ 2797.984 \cdot i^{*} \cdot\left(\frac{i^{*}}{i_{\mathrm{s}}}-1\right)+1.821 \%, & \text { for } I_{\sigma}\end{array}\right.$.

As shown in Figs. 2 and 5, the calculated results had a good agreement with the measured ones. Equation (15) derived herein was validated. It was also proved that the SCC behavior was controlled by the film suppressed anodic dissolution mechanism in these circumstances.

\subsection{Effect of Chloride Ion on the SCC Behavior}

It was believed that chloride ion could enhance the transformation of passive films from stable oxide to unstable hydroxyl groups and facilitates pitting [26]. Most cracks evolved in the interior of single pit or pitting clusters, so pitting was a precursor to SCC [27]. The same phenomena were seen in this work. As shown in Fig. 3, the existence of chloride ion promoted the occurrence and growth of pitting and the resultant brittle cracking. The polarization curves in Fig. 7a, b indicated that chloride ion mainly affected passive region. On the one hand, higher amount of chloride ion led to a narrower passive region due to the catalytic effect of this ion on liberating $\mathrm{Fe}^{3+}$ from the ferric oxide film [24], which caused the breakdown potential of the ferric oxide film to be reduced to its Flade potential [28]. On the other hand, it led to a higher passive current density manifested in the considerably reduced $i_{\mathrm{s}}$ and $R_{\mathrm{p}}$. Therefore, the SCC behaviors of X80 steel in these circumstances depended on film rupture and anodic dissolution assisted by chloride ion. It can be concluded that chloride ion was detrimental to the properties of passive films. The existence of chloride ion caused a greatly reduced passivation tendency, while its concentration determined the stability of passive films, thereby affecting the dissolution rate of the steel matrix at film-ruptured sites.

\subsection{Effect of pH on the SCC Behavior}

In this work, the $\mathrm{pH}$ value was directly associated with the relative concentrations of bicarbonate and carbonate ions in $0.15 \mathrm{~mol} / \mathrm{L} \mathrm{Na}_{2} \mathrm{CO}_{3} / \mathrm{NaHCO}_{3}$ solutions. The solution with a $\mathrm{pH}$ of 8.31 mainly contained bicarbonate ion. As shown in Fig. 7c, d, there was no stable passive region but high $i_{\mathrm{s}}$ and $i_{\mathrm{f}}$. From this point of view, the criterion described by Eq. (1) was still feasible. According to our previous research [29], the rupture of passive films was promoted by excessive bicarbonate ion owing to the formation of the soluble composite ion $\mathrm{Fe}\left(\mathrm{CO}_{3}\right)_{2}^{2-}$ [30]. Therefore, low $\mathrm{pH}$ led to the fast dissolution of crack tips along slip steps, leaving cleavage lamellae at the edge of the fracture surface (Fig. 6c). With the increase in $\mathrm{pH}$, carbonate ion gradually became dominant in the solution. Particularly when the $\mathrm{pH}$ reached as high as 11.64 , the solution contained almost exclusively the carbonate ion. Furthermore, the increase in $\mathrm{pH}$ value, or rather, the relative concentration of carbonate ion resulted in wider passive region, lower passive current density (Fig. 7c, d), and drastically increased $R_{\text {po }}$ (Table 1). These were different from the indications in Ref. [6] that the $\mathrm{pH}$ higher than 5 had no significant effect on electrochemical processes. It can be inferred that this difference in electrochemical behaviors was attributed to the formation of stable and tenacious passive films. Firstly, these films can restrict the transfer rate of aggressive ions and greatly reduced the risk of crack initiation [13]. Secondly, solution with higher carbonate ion concentration seemed to provide higher repassivation possibility [31]. Once the film ruptured, the exposed steel matrix was instantaneously repassivated within such a high-pH solution, so that cracking was suppressed or ceased. Thirdly, the cathodic polarization curves showed a decreased current density with the increase in $\mathrm{pH}$, suggesting a reduced oxygen reduction rate. It meant that the anodic dissolution at crack tips controlled by oxygen reduction was retarded. That was why the SCC susceptibility of X80 steel was decreased with the increase in $\mathrm{pH}$ at passive potential, or there was even no susceptibility when the $\mathrm{pH}$ value reached 11.64 .

\section{Conclusions}

(1) The SCC behavior of X80 pipeline steel conformed to the film suppressed anodic dissolution mechanism in concentrated carbonate/bicarbonate solutions at passive potential, since the overall electrode reaction rate was dominated by intensive filming process. The criteria for evaluating the SCC susceptibility of X80 steel in these circumstances were proposed and validated based on the distinctive electrochemical measurements.

(2) The SCC behavior of X80 steel depended on film rupture and anodic dissolution assisted by chloride ion. The existence of chloride ion caused a greatly reduced passivation tendency, while its concentration 
determined the stability of passive films, thereby affecting the dissolution rate of the steel matrix at film-ruptured sites.

(3) Higher $\mathrm{pH}$ was responsible for the formation of stable and tenacious passive films, high repassivation capability, and low anodic dissolution rate at crack tips, leading to the greatly reduced SCC susceptibility.

Acknowledgments This work was financially supported by the National Natural Science Foundation of China (Nos. 51471034, 51131001 and 51171025). Many thanks to Dr. Ri Qiu for the fruitful discussion.

\section{References}

[1] C. Manfredi, J.L. Otegui, Eng. Fail. Anal. 9, 495 (2002)

[2] L. Zhang, X.G. Li, C.W. Du, Y.Z. Huang, Mater. Des. 30, 2259 (2009)

[3] M.C. Yan, J.Q. Wang, E.H. Han, W. Ke, Corros. Sci. 50, 1331 (2008)

[4] R.N. Parkins, W.K. Blanchard Jr., B.S. Delanty, Corrosion 50, 394 (1994)

[5] G.A. Zhang, Y.F. Cheng, Electrochim. Acta 55, 316 (2009)

[6] Z.Y. Liu, C.W. Du, X. Zhang, F.M. Wang, X.G. Li, Acta Metall. Sin. (Engl. Lett.) 26, 489 (2013)

[7] B.Y. Fang, A. Atrens, J.Q. Wang, E.H. Han, Z.Y. Zhu, W. Ke, J. Mater. Sci. 38, 127 (2003)

[8] R.N. Parkins, Corrosion 43, 130 (1987)

[9] V.A. Alves, C.M.A. Brett, Corros. Sci. 44, 1949 (2002)
[10] W.S. Li, J.L. Luo, Corros. Sci. 44, 1695 (2002)

[11] J.W. Schultze, M.M. Lohrengel, Electrochim. Acta 45, 2499 (2000)

[12] A.Q. Fu, Y.F. Cheng, Corros. Sci. 52, 612 (2010)

[13] G.Z. Meng, C. Zhang, Y.F. Cheng, Corros. Sci. 50, 3116 (2008)

[14] B.T. Lu, F. Song, M. Gao, M. Elboujdaini, Corros. Sci. 52, 4064 (2010)

[15] D.G. Li, Y.R. Feng, Z.Q. Bai, J.W. Zhu, M.S. Zheng, Appl. Surf. Sci. 254, 2837 (2008)

[16] D.G. Li, Y.R. Feng, Z.Q. Bai, J.W. Zhu, M.S. Zheng, Electrochim. Acta 52, 7877 (2007)

[17] R.N. Parkins, Corrosion 52, 363 (1996)

[18] R.N. Parkins, Corros. Sci. 20, 147 (1980)

[19] Z.Y. Liu, L. Lu, Y.Z. Huang, C.W. Du, X.G. Li, Corros. 70(7), 678 (2014)

[20] L. Fan, Z.Y. Liu, C.W. Du, X.G. Li, Acta Metall. Sin. (in Chinese) 49, 689 (2013)

[21] Z.Y. Liu, X.G. Li, C.W. Du, G.L. Zhai, Y.F. Cheng, Corros. Sci. 50, 2251 (2008)

[22] B.R. Linter, G.T. Burstein, Corros. Sci. 41, 117 (1999)

[23] J.K. Heuer, J.F. Stubbins, Corros. Sci. 41, 1231 (1999)

[24] X. Liu, X. Mao, Scr. Metall. Mater. 33, 145 (1995)

[25] Y.F. Cheng, J. Mater. Sci. 42, 2701 (2007)

[26] C.S. Zhang, J.L. Luo, D. Munoz-Paniagua, P.R. Norton, Thin Solid Films 503, 149 (2006)

[27] P. Liang, C.W. Du, X.G. Li, X. Chen, L. Zhang, Int. J. Min. Metall. Mater. 16, 407 (2009)

[28] J. Kruger, Corros. Sci. 29, 149 (1989)

[29] L. Fan, C.W. Du, Z.Y. Liu, X.G. Li, Int. J. Min. Metall. Mater. 20, 645 (2013)

[30] D.H. Davies, G.T. Burstein, Corrosion 36, 416 (1980)

[31] J.Q. Wang, A. Atrens, Corros. Sci. 45, 2199 (2003) 